\title{
Original
}

\section{Application of 18-item DEOS for Dementia Elderly People Living at Home and Its Reliability and Validity}

\author{
Hiromi Tsujimura $^{1}$, Kikuko Iwanaga ${ }^{2}$ and Yumi Sato ${ }^{1}$ \\ 1 Gunma University Graduate School of Health Sciences, 3-39-22 Showa-machi, Maebashi, Gunma 371-8514, Japan \\ 2 Niigata College of Nursing, 240 Shinnan-cho, Joetsu, Niigata 943-0147, Japan
}

\section{Abstract}

Objectives: The aim of this study was to examine the reliability and validity of the 18 items of the Dementia Elderly Odayaka Scale (DEOS) in elderly people with dementia who lived at home. Methods: Ninety-three elderly people with dementia who lived at home and utilized a home-visit nursing service were enrolled. Three evaluators (two nurses and one family caregiver per subject) evaluated each subject twice at an interval of about two weeks. Results: A clinical dementia rating of 2 or 3 was the most common (30\% of enrolled patients). With respect to the intra-rater and inter-rater reliability, the average difference between the two scores ranged between 0.5 and 0 . 8 for each item. The intraclass correlation coefficient using the test-retest method was $0.9(P<0.01)$, while that of the total scores evaluated by the nurses and family members was $0.7-0.8(P<0.01)$. The overall Cronbach $\alpha$ coefficient for the 18-item DEOS was 0.95, while the coefficients for each area ranged from 0.86-0.91. Based on a factor analysis, the 18 items were classified into 3 domains: [Personhood], [Interactions with surroundings] and [Expression of emotions]. Conclusion: The reliability and validity of the 18 items of the DEOS were verified.

\begin{tabular}{l} 
Article Information \\
\hline Key words: \\
dementia, \\
elderly people, \\
well-being, \\
scale, \\
home care \\
\hline Publication history: \\
Received: February 17, 2017 \\
Revised: June 14, 2017 \\
Accepted: June 15, 2017 \\
Corresponding author: \\
Hiromi Tsujimura \\
Gunma University Graduate School of Health Sciences, \\
3-39-22 Showa-machi, Maebashi, Gunma 371-8514, Japan \\
Tel: +81-27-220-8928 \\
E-mail: tujimura @ gunma-u.ac.jp \\
\hline
\end{tabular}

\section{Research background}

The Ministry of Health, Labour, and Welfare (MHLW) of Japan has estimated that more than 3.45 million elderly Japanese individuals with dementia were certified as being eligible to receive Long-term Care (LTC) Insurance in 2015 and that 10\% of Japanese subjects over the age of 65 years suffer from dementia. ${ }^{1} \quad$ The number of elderly people with dementia has increased rapidly in Japan over the past 10 years. A report estimated that the total number of Japanese individuals with dementia was 1.49 million in 2002, but this number was expected to reach 4.7 million by 2025 , representing $13 \%$ of the Japanese population over 65 years of age. ${ }^{2}$ Japan has experienced an unprecedented increase in the aging of its society, and the prevalence of elderly people with dementia also continues to increase year by year. With this in mind, the Japanese national government announced a "Five-Year Plan for the Promotion of Measures Against Dementia (Orange Plan)" in 2012. This plan was aimed at the realization of a society in which persons with dementia can live with dignity in a pleasant and familiar environment for as long as possible. $^{3} \quad$ Accordingly, the current direction of dementia care is to respect "personhood" and the patient's abilities. ${ }^{4}$

Through clinical experience, research, and the caring of a family member with dementia, one of the authors noticed that elderly subjects with dementia can maintain a good state and "personhood" despite a diagnosis of dementia. The utility of a scale, known as the Dementia Elderly Odayaka Scale (DEOS), for evaluating elderly people with dementia has been 
verified. The name of this scale contains the word odayaka, which in Japanese represents a good state as viewed by others. Kitwood (1992) defined the meaning of well-being as "to have self-esteem and to express self-emotion and to show self-expression and affection." In addition, the Japanese word odayaka encompasses not only mental stability, but also a good relationship with one's surroundings. Thus, it includes a good state for family caregivers as well as for people with dementia.

A literature review reveals several scales for assessing the state of dementia, including cognitive function tests and evaluations of dementia severity; the evaluation of mental function, behavior disorders and activities of daily life (ADL) has also been reported. ${ }^{6}$ From a behavioral psychology perspective, these scales often evaluate negative aspects of dementia. When assessing positive aspects, a quality of life (QOL) measure is often used in subjects with or without dementia. Brod $(1999)^{7}$ developed the Dementia Quality of Life Instrument (DQOL) to measure the QOL of elderly people with dementia subjectively in an interview format. Suzuki $(2005)^{8}$ has since developed a Japanese version of the DQOL and has verified its reliability and validity. However, the subjects of the present study were elderly people with mild dementia who could answer questions correctly. As a measure of the QOL of elderly people with dementia, Terada $(2002)^{9}$ developed a health-related QOL measure for Japanese subjects. This scale can be used to assess both negative and positive aspects of elderly people with dementia. In addition, Rabins and Kasper (1997) $)^{10-11}$ have developed the Alzheimer's disease health-related quality of life (AD-HRQL) scale. A Japanese version of this scale was created by Abe (1998) and YamamotoMitani (2002). ${ }^{12-13}$ These comprehensive QOL scales can be used to evaluate the health of subjects with Alzheimer disease based on evaluations made by others, and they can also be used to evaluate positive aspects. In general, when measuring the QOL of elderly people with dementia, it is important to consider "what they can do," 14 rather than "what they can' t do." Subjective evaluations made by such individuals should be respected. However, these subjects have memory and cognitive impairment symptoms as core features of their disease. ${ }^{15}$ Therefore, QOL evaluations performed by others, such as family members and caregivers, should also be completed.

Regarding the 25 -item of the DEOS reported in a previous study, ${ }^{16}$ some facility staff members mentioned that "there are similar question items" and "I would like to reduce the number of questions" among their feedback. Furthermore, the inter-rater reliability of the scale needed to be verified. Consequently, an 18-item DEOS ${ }^{17}$ for elderly people with dementia living in healthcare facilities was developed. In addition, since the use of home care services is expected to increase in the future, the reliability and validity of the 18-item DEOS should also be verified for elderly people with dementia living at home. In the presently reported survey, both family members and nurses were included as evaluators, since the DEOS contains several items regarding the individual state of the subject. For example, some items concern the subject's daily life and personality, as well as their mental and social states. Thus, family members, who are in close contact with the subjects with dementia, are likely to provide useful evaluations of the subject' $s$ actual condition. In addition, family members are likely to be the primary caregivers at home. Therefore, in considering at-home dementia care, the actual situation, including the states of the family members, should be investigated.

\section{Objectives}

The aim of this study was to apply the 18 -item DEOS to elderly people with dementia living at home and to examine its reliability and validity.

\section{Operational definition of odayaka}

In Japanese, the word odayaka generally means mental stability and quietness. ${ }^{18}$ In the present paper, odayaka was additionally regarded as meaning an ability to interact with one's surroundings and to live in one's own manner despite a decline in cognitive function as a result of dementia. ${ }^{17}$

\section{Research methods}

\section{Participants}

\section{1-1. Subjects}

Ninety-three elderly people with dementia who were 65 years old or over and who lived at home and utilized home-visit nursing services within a single prefecture (Prefecture A) were enrolled. The subjects in this study were regarded as having been diagnosed with dementia based on the written opinions of the doctors in charge of their care. In consideration of the burden on the evaluators, we selected 15 facilities, each with a large number of nurses and users, from a list provided by the Home-Visit Nursing Facilities Association in Prefecture A and the Welfare and Medical Service Network System (WAM NET:http://www. wam.go.jp/).

\section{1-2. Evaluators}

The evaluators were nurses working for the 15 home-visit nursing services included in this study and the family members of the subjects (living together or living separately but close by). Each evaluator had to be aware of the subject's daily life. Family members were not evaluated on their cognitive function in consideration of their mental burden, etc. The nurses were asked to determine whether any communication problems were present when conducting discussions with the family members.

\section{Evaluation methods}

The intra-rater and inter-rater reliability were examined. Three evaluators (two nurses and one fam- 
ily member) evaluated each subject twice at an interval of about two weeks. When determining the test-retest reliability, a very short time interval can create a carryover effect, whereas a longer interval increases the chance that a change in status could occur. Most investigators have chosen an interval ranging from 2 days to 2 weeks. ${ }^{19}$ An interval of about 2 weeks was appropriate in this study because transient changes in emotions and attitudes were not evaluated.

\section{Recruitment method and informed consent for subjects and evaluators}

After obtaining written consent from the facility chief, the administrators of the home-visit nursing services selected subjects based on the cognitive function of the family members and the burden of this research, etc. Next, the administrator selected 2 nurses (excluding newcomers) who often visited each subject at home. The administrator verbally explained the study to each nurse using the research document. The nurses consented to participate in the research by completing the research form. For family consent, the nurse verbally explained the study to each family member using the research document and obtained each family member's signature. For the subjects, the nurse or a family member explained the study in a manner suited to the subject's cognitive function.

\section{Research forms}

\section{4-1. Eighteen-item DEOS (Document 1-2)}

The 18-item DEOS is completed by an observer and is used to evaluate the daily life of a subject. The scale was revised to include 18 items, from among an original 25 items, based on the results of a previous study. ${ }^{5}$ The questions consisted of items regarding [Interactions with surroundings], [Personhood], and [Expression of emotions]. The maximum score for the 18 items was 72 points, with each item being evaluated using a 4-point Likert scale as follows: "Applicable," 4 points; "Somewhat applicable," 3 points; "Not very applicable," 2 points; and "Not applicable," 1 point.

\section{4-2. Basic characteristic}

The following characteristics of the subjects and evaluators were examined.

Subjects (elderly people with dementia): sex, age, diagnosis, level of long-term care (LTC), independence level in daily life, and clinical dementia rating (CDR). The CDR, which was first reported by Hughes et al., ${ }^{20}$ is used to characterize six domains of cognitive and functional performance and related dementias (memory, orientation, judgment and problem solving, community affairs, home and hobbies, and personal care).

Evaluators (nurses): sex, clinical experience with dementia care, experience caring for the subject.

Evaluators (family members): sex, relationship with the subject, experience caring for the subject.

\section{Research period}

The research period lasted from April 2013 to July 2014.

\section{Analysis}

For each subject, three evaluators completed the 18-item DEOS on two separate occasions. The first evaluation had a Kaiser-Meyer-Olkin (KMO) measure of sampling adequacy that was as high as 0.94 when applied in a factor analysis, reliability analysis, interrater reliability, and analysis of basic characteristics. To determine the inter-rater reliability, the average score obtained by two nurses and the score obtained by one family member were analyzed. For the statistical analysis, the IBM statistical package SPSS $22.0 \mathrm{~J}$ was utilized according to the following procedure.

First, an exploratory factor analysis (EFA) was conducted to investigate latent factors among the observed variables. Based on the content of each item and the factor loadings and after confirming that the 18 items could be divided into 3 areas, in the reliability analysis, the internal consistency from the item-total correlation and the Cronbach $\alpha$ coefficient between the whole area and each area were examined. When examining the test-retest reliability for the same evaluator, the intraclass correlation coefficient (ICC) of the total score for the first and second times was calculated for each nurse and for each family member. To examine the inter-rater reliability, the ICC of the total scores obtained by the nurses and family members and the score differences between the nurses and family members and between two nurses was examined for each question item. In addition, the score distributions according to the subjects' characteristics (CDR, LTC level, and diagnosis) were also analyzed. The MannWhitney $U$ test was used to compare differences between patients with Alzheimer disease (AD) and those with vascular dementia (VaD).

\section{Ethical considerations}

The facility administrators encrypted the names of the subjects and evaluators and managed them in a ledger, to which the researchers did not have access. The subjects and evaluators were given an oral and written explanation regarding their freedom to withdraw from the study at any time.

This study was approved by the research ethics committee on Epidemiological Studies of Gunma University Faculty of Medicine (No. 24-51).

\section{Results}

\section{Characteristics of subjects and evaluators}

\section{1-1. Subjects (Table 1)}

Ninety-three subjects (28 men [30.1\%], 64 women $[68.8 \%], 1$ not indicated [1.1\%]) with an average age of $85.1 \pm 7.0$ years were included in the study. Thirtytwo subjects (34.4\%) were diagnosed as having AD, 19 (20.4\%) were diagnosed as having $\mathrm{VaD}, 5$ (5.4\%) were diagnosed as having dementia with Lewy bodies (DLB), and 1 (1.1\%) was diagnosed as having frontotemporal dementia (FTD); a detailed diagnosis of dementia was unavailable for the remaining 36 subjects (38.7\%). An LTC level of 1 and an LTC level of 5 
were the most frequent (25\% each). The largest proportion of elderly subjects with dementia (23\%) had a daily life independence level of IV. CDR of 2 and a CDR of 3 were the most frequent (30\% each).

\begin{tabular}{|c|c|c|c|}
\hline & & $\mathrm{n}$ & $\%$ \\
\hline \multicolumn{4}{|l|}{ Sex } \\
\hline & male & 28 & 30.1 \\
\hline & female & 64 & 68.8 \\
\hline & not indicated & 1 & 1.1 \\
\hline \multicolumn{4}{|c|}{ Average age $(85.1 \pm 7.0)$} \\
\hline & male & $81.6 \pm 5.9$ & \\
\hline & female & $86.5 \pm 7.0$ & \\
\hline \multicolumn{4}{|c|}{ Diagnosis* } \\
\hline & $\mathrm{AD}$ & 32 & 34.4 \\
\hline & $\mathrm{VaD}$ & 19 & 20.4 \\
\hline & DLB & 5 & 5.4 \\
\hline & FTD & 1 & 1.1 \\
\hline & others & 36 & 38.7 \\
\hline \multicolumn{4}{|c|}{ LTC (Long-term care) } \\
\hline & Requiring support 1 & 1 & 1.1 \\
\hline & Requiring support 2 & 2 & 2.2 \\
\hline & LTC level 1 & 24 & 25.8 \\
\hline & LTC level 2 & 11 & 11.8 \\
\hline & LTC level 3 & 12 & 12.9 \\
\hline & LTC level 4 & 19 & 20.4 \\
\hline & LTC level 5 & 23 & 24.7 \\
\hline & not indicated & 1 & 1.1 \\
\hline
\end{tabular}

\begin{tabular}{lcrr}
\hline Independence level in daily life & & & \\
& I & 5 & 5.4 \\
II a & 15 & 16.1 \\
II b & 19 & 20.4 \\
IIIa & 18 & 19.4 \\
IIIb & 11 & 11.8 \\
IV & 21 & 22.6 \\
M & 4 & 4.3 \\
\hline
\end{tabular}

CDR (Clinical Dementia Rating)

$\begin{array}{rrr}0.5 & 9 & 9.7 \\ 1 & 22 & 23.7 \\ 2 & 30 & 32.3 \\ 3 & 32 & 34.4\end{array}$

* AD : Alzheimer disease

VaD : Vascular dementia

DLB : Dementia with Lewy bodies

FTD : Frontotemporal dementia

\section{1-2. Evaluators}

Seventy-nine nurses participated as evaluators, (77 women $[97.5 \%], 2$ men $[2.5 \%])$. In this survey, each nurse evaluated between one and eight subjects. Their clinical experience related to dementia care was $10.5 \pm$ 7.9 years, and their experience nursing each subject ranged from 0.1 to 11.8 years.

Ninety-three family members participated as evaluators (38 men $[40.9 \%], 49$ women $[52.7 \%]$, and 6 not indicated $[6.4 \%])$. Twenty-seven family members were spouses (12 husbands and 15 wives), 53 were children (21 sons, 24 daughters, 8 sons' wives), 2 were brothers, 2 were sisters, and 4 were other relations; the remaining 5 evaluators did not provide an answer. The period during which they had provided care for the subjects was $3.9 \pm 3.5$ years.

\section{Factor analysis (Table 2)}

In the following section, an item (subscale) of the 18-item DEOS is indicated by quotation marks and the factor name in the factor analysis is indicated by square brackets. In a factor analysis of the 18 items, the interpretation of each factor was made based on items with factor loadings of 0.3 or above. Although the factor loadings of two items (Q2 and Q16) were 0.28, these items were judged to be necessary elements constituting the subscale and were included.

Factor I was named [Personhood] based on high factor loadings for "Being able to insist on one's will and wishes," "Being able to work hard at what one likes," "Being able to groom oneself (makeup, hair style, clothing, belongings)," and "Being able to perform one's daily routine at one's own pace." Factor II was named [Interactions with surroundings] based on high factor loadings for "Being able to pay attention to others," "Being able to be kind to others," and "Being able to spend time with a friendly person," Factor III was named [Expression of emotions] based on high factor loadings for "Being able to express joy with a smile," and "Being able to express emotions (such as pleasure and suffering)." For items with high factor loadings across 2 factors, the items were examined based on their factor loadings and contents. As a result, "Being able to do something for others" was classified as factor I, and "Being able to interact with surrounding people" was classified as Factor II.

The correlation coefficients between the factors were 0.75 for Factor I and Factor II, 0.75 for Factor I and Factor III, and 0.74 for Factor II and Factor III.

\section{Reliability (Table 3) \\ 3-1. Cronbach $\alpha$ coefficient and item-total correla- tion}

The overall Cronbach $\alpha$ coefficient for the 18-item DEOS was 0.95 , while the $\alpha$ coefficients for each area were 0.90 for [Personhood], 0.91 for [Interactions with surroundings], and 0.86 for [Expression of emotions].

Regarding the item-total correlation for each area, [Personhood] was 0.64 to 0.77 , [Interactions with surroundings] was 0.73 to 0.80 , and [Expression of emotions] was 0.57 to 0.76 .

\section{3-2. Intra-rater reliability}

The total average scores of the test-retests for the evaluations made by the nurses were 46.0 points for the first evaluation and 47.3 points for the second evaluation, and the ICC between the first and second evaluations was $0.93(P<0.01)$. For the family members, the ICC between the first and second evaluations was 0.97 $(P<0.01)$, with 50.4 points for the first evaluation and 48.9 points for the second evaluation.

3-3. Score differences between the evaluations made by the nurses and the family members (Table 4-1)

For all 18 items, the average score differences 


\begin{tabular}{|c|c|c|c|c|}
\hline & item & factor I & factor II & factor III \\
\hline Q12 & Being able to insist on his/her will and wish & .80 & -.21 & .15 \\
\hline Q18 & Being able to work hard at what he/she like & .73 & -.05 & -.03 \\
\hline Q11 & Being able to groom (makeup, hair style, clothing, belongings) & .73 & .08 & -.06 \\
\hline Q 9 & Being able to perform the daily routine at his/her own pace & .71 & .07 & -.05 \\
\hline Q 8 & Being able to enjoy an old tale & .70 & .21 & -.03 \\
\hline Q15 & Being able to do something for others & .38 & .42 & -.06 \\
\hline Q13 & Being able to have pride as a human being & .38 & .21 & .31 \\
\hline Q16 & Being able to be positive not negative & .28 & .25 & .26 \\
\hline Q 4 & Being able to pay attention to others & -.03 & 1.04 & -.14 \\
\hline Q 6 & Being able to be kind to others & -.17 & .78 & .29 \\
\hline Q 3 & Being able to spend time with a friendly person & .24 & .50 & .07 \\
\hline Q 1 & Being able to interact with the surrounding people & .53 & .32 & .06 \\
\hline Q 2 & Being able to listen calmly to others & .27 & .28 & .30 \\
\hline Q14 & Being able to express joy with a smile & -.21 & .05 & 1.00 \\
\hline Q10 & Being able to express emotions (such as pleasure and suffering) Expression of emotions & .32 & -.14 & .65 \\
\hline Q 5 & Being able to love small children and animals & -.03 & .33 & .46 \\
\hline Q17 & Being able to feel relaxed & .25 & -.07 & .50 \\
\hline \multirow[t]{7}{*}{ Q 7} & Being able to enjoy humor & .33 & .19 & .40 \\
\hline & Eigenvalue & 9.76 & 0.67 & 0.63 \\
\hline & Contribution rate & 54.20 & 3.74 & 3.47 \\
\hline & Cumulative contribution rate & 54.20 & 57.93 & 61.40 \\
\hline & Correlation coefficients between factors I & & & \\
\hline & II & .75 & & \\
\hline & III & .75 & .74 & \\
\hline
\end{tabular}

Maximum likelihood method, promax rotation

* DEOS : Dementia Elderly Odayaka Scale

Table 3 Reliability analysis among each area (18-items)

\begin{tabular}{|c|c|c|c|c|c|c|}
\hline \multicolumn{2}{|c|}{ alpha $=.95$} & alpha & \multicolumn{2}{|c|}{$\mathrm{M} \pm \mathrm{SD}$} & \multirow[t]{2}{*}{$\begin{array}{c}\text { Corrected Item-Total } \\
\text { Correlation }\end{array}$} & \multirow[t]{2}{*}{$\begin{array}{c}\text { Alpha if } \\
\text { Item Deleted }\end{array}$} \\
\hline & Personhood (8 items) & .90 & & & & \\
\hline Q 8 & Being able to enjoy an old tale & & 2.98 & 1.05 & .77 & .88 \\
\hline Q 9 & Being able to perform the daily routine at his/her own pace & & 2.89 & 1.00 & .66 & .89 \\
\hline Q11 & Being able to groom (makeup, hair style, clothing, belongings) & & 2.13 & 1.01 & .72 & .89 \\
\hline Q12 & Being able to insist on his/her will and wish & & 2.90 & 1.03 & .65 & .89 \\
\hline Q13 & Being able to have pride as a human being & & 2.86 & 1.02 & .76 & .88 \\
\hline Q15 & Being able to do something for others & & 1.91 & 0.92 & .65 & .89 \\
\hline Q16 & Being able to be positive not negative & & 2.50 & 0.94 & .64 & .89 \\
\hline \multirow[t]{2}{*}{ Q18 } & Being able to work hard at what he/she like & & 2.02 & 0.97 & .66 & .89 \\
\hline & Interaction with the surroundings (5 items) & .91 & & & & \\
\hline Q 1 & Being able to interact with the surrounding people & & 2.82 & 1.01 & .76 & .89 \\
\hline Q 2 & Being able to listen calmly to others & & 2.98 & 0.93 & .73 & .89 \\
\hline Q 3 & Being able to spend time with a friendly person & & 2.81 & 1.07 & .73 & .89 \\
\hline Q 4 & Being able to pay attention to others & & 2.69 & 1.03 & .80 & .88 \\
\hline \multirow[t]{2}{*}{ Q 6} & Being able to be kind to others & & 2.93 & 0.98 & .80 & .88 \\
\hline & Expression of emotions (5 items) & .86 & & & & \\
\hline Q 5 & Being able to love small children and animals & & 2.73 & 1.05 & .64 & .85 \\
\hline Q 7 & Being able to enjoy humor & & 2.69 & 0.99 & .73 & .82 \\
\hline Q10 & Being able to express emotions (such as pleasure and suffering) & & 2.96 & 0.93 & .72 & .82 \\
\hline Q14 & Being able to express joy with a smile & & 3.30 & 0.85 & .76 & .82 \\
\hline Q17 & Being able to feel relaxed & & 3.03 & 0.89 & .57 & .86 \\
\hline
\end{tabular}

(absolute values) between the evaluations made by the nurses and the family members ranged from 0.5 to 0.8 (range, 0 to 3 ).

\section{3-4. Score differences between the evaluations made by the two nurses (Table 4-2)}

For all 18 items, the average score differences (absolute values) between the evaluations made by the 2 nurses ranged from 0.5 to 0.8 (range, 0 to 3 ). 
Table 4-1 Scoring difference between 2 evaluators (family members and nurses)

$\mathrm{n}=93$

\begin{tabular}{|c|c|c|c|c|c|c|c|c|c|c|c|c|c|c|c|}
\hline $\begin{array}{l}18 \text { items } \\
\text { DEOS }\end{array}$ & -3 & -2.5 & -2 & -1.5 & -1 & -0.5 & 0 & 0.5 & 1 & 1.5 & 2 & 2.5 & 3 & $\begin{array}{c}\text { total of } \\
\text { absolute value }\end{array}$ & $\begin{array}{c}\text { Average of } \\
\text { absolute value }\end{array}$ \\
\hline Q 1 & 0 & 0 & 1 & 3 & 14 & 16 & 28 & 11 & 14 & 3 & 3 & 0 & 0 & 58.5 & 0.6 \\
\hline Q 2 & 0 & 0 & 1 & 3 & 10 & 9 & 32 & 18 & 16 & 1 & 2 & 0 & 0 & 51.5 & 0.6 \\
\hline Q 3 & 0 & 1 & 2 & 3 & 12 & 12 & 26 & 10 & 13 & 7 & 4 & 1 & 0 & 68 & 0.7 \\
\hline Q 4 & 0 & 0 & 5 & 4 & 14 & 9 & 25 & 16 & 12 & 6 & 0 & 1 & 0 & 66 & 0.7 \\
\hline Q 5 & 0 & 0 & 3 & 2 & 11 & 2 & 29 & 12 & 15 & 6 & 8 & 3 & 0 & 74.5 & 0.8 \\
\hline Q 6 & 0 & 1 & 3 & 3 & 9 & 8 & 34 & 10 & 17 & 4 & 2 & 0 & 1 & 61 & 0.7 \\
\hline Q 7 & 0 & 0 & 4 & 4 & 9 & 14 & 30 & 11 & 8 & 8 & 4 & 0 & 0 & 63.5 & 0.7 \\
\hline Q 8 & 0 & 1 & 1 & 3 & 13 & 7 & 36 & 12 & 11 & 6 & 2 & 0 & 0 & 55.5 & 0.6 \\
\hline Q 9 & 1 & 1 & 0 & 4 & 12 & 11 & 28 & 12 & 10 & 6 & 7 & 1 & 0 & 70.5 & 0.8 \\
\hline Q10 & 0 & 1 & 0 & 5 & 8 & 10 & 28 & 16 & 19 & 3 & 1 & 1 & 0 & 59 & 0.6 \\
\hline Q11 & 0 & 0 & 1 & 1 & 8 & 13 & 37 & 11 & 11 & 6 & 4 & 1 & 0 & 54 & 0.6 \\
\hline Q12 & 0 & 0 & 3 & 3 & 12 & 14 & 32 & 13 & 11 & 3 & 1 & 0 & 1 & 56.5 & 0.6 \\
\hline Q13 & 2 & 0 & 2 & 2 & 7 & 6 & 34 & 14 & 13 & 5 & 5 & 1 & 0 & 63 & 0.7 \\
\hline Q14 & 0 & 0 & 1 & 4 & 17 & 6 & 37 & 20 & 3 & 3 & 1 & 1 & 0 & 50 & 0.5 \\
\hline Q15 & 0 & 0 & 0 & 0 & 14 & 17 & 34 & 10 & 5 & 5 & 6 & 0 & 1 & 55 & 0.6 \\
\hline Q16 & 0 & 0 & 2 & 3 & 11 & 10 & 24 & 20 & 13 & 5 & 1 & 1 & 0 & 59.5 & 0.7 \\
\hline Q17 & 0 & 0 & 3 & 5 & 7 & 9 & 26 & 18 & 21 & 1 & 2 & 0 & 0 & 60.5 & 0.7 \\
\hline Q18 & 0 & 0 & 1 & 3 & 8 & 8 & 36 & 15 & 11 & 6 & 4 & 1 & 0 & 56.5 & 0.6 \\
\hline
\end{tabular}

The nurse's scores were the average of two people

Table 4-2 Absolute value of scoring difference between 2 evaluators (2 nurses)

\begin{tabular}{|c|c|c|c|c|c|c|}
\hline $\begin{array}{l}18 \text { items } \\
\text { DEOS }\end{array}$ & 0 & 1 & 2 & 3 & total vallue & Average value \\
\hline Q 1 & 43 & 32 & 7 & 1 & 49 & 0.6 \\
\hline Q 2 & 43 & 30 & 8 & 1 & 49 & 0.6 \\
\hline Q 3 & 35 & 34 & 13 & 1 & 63 & 0.8 \\
\hline Q 4 & 40 & 35 & 7 & 1 & 52 & 0.6 \\
\hline Q 5 & 43 & 24 & 10 & 1 & 47 & 0.6 \\
\hline Q 6 & 48 & 26 & 9 & 0 & 44 & 0.5 \\
\hline Q 7 & 32 & 36 & 14 & 1 & 67 & 0.8 \\
\hline Q 8 & 41 & 29 & 13 & 0 & 55 & 0.7 \\
\hline Q 9 & 33 & 33 & 15 & 2 & 69 & 0.8 \\
\hline Q10 & 30 & 36 & 15 & 1 & 69 & 0.8 \\
\hline Q11 & 42 & 30 & 9 & 2 & 54 & 0.7 \\
\hline Q12 & 44 & 32 & 5 & 1 & 45 & 0.5 \\
\hline Q13 & 37 & 26 & 15 & 2 & 62 & 0.8 \\
\hline Q14 & 44 & 33 & 5 & 1 & 46 & 0.6 \\
\hline Q15 & 44 & 32 & 7 & 0 & 46 & 0.6 \\
\hline Q16 & 33 & 38 & 11 & 1 & 63 & 0.8 \\
\hline Q17 & 42 & 33 & 8 & 0 & 49 & 0.6 \\
\hline Q18 & 44 & 29 & 7 & 3 & 52 & 0.6 \\
\hline
\end{tabular}

Table 5 ICC between 2 evaluators

\begin{tabular}{cc}
18 items & $\mathrm{n}=93$ \\
\hline DES & Nurse and family \\
\hline Q 1 & $.66^{* *}$ \\
Q 2 & $.67^{* *}$ \\
Q 3 & $.57^{* *}$ \\
Q 4 & $.59^{* *}$ \\
Q 5 & $.47^{* *}$ \\
Q 6 & $.54^{* *}$ \\
Q 7 & $.55^{* *}$ \\
Q 8 & $.67^{* *}$ \\
Q 9 & $.48^{* *}$ \\
Q10 & $.58^{* *}$ \\
Q11 & $.65^{* *}$ \\
Q12 & $.66^{* *}$ \\
Q13 & $.51^{* *}$ \\
Q14 & $.59^{* *}$ \\
Q15 & $.56^{* *}$ \\
Q16 & $.57^{* *}$ \\
Q17 & $.54^{* *}$ \\
Q18 & $.61^{* *}$ \\
\hline
\end{tabular}

The nurse's score is the average of two people

\section{3-5. Inter-rater reliability}

The ICCs of the total scores between the evaluations made by the 2 nurses and those made by the family members were $0.75(P<0.01)$ for the first evaluation and $0.73(P<0.01)$ for the second evaluation. In addition, the ICCs for each question item between the evaluations made by the nurses and those made by the family members ranged from 0.47 to $0.67 \quad(P<0.01)$ (Table 5).

\section{Validity (Content validity)}

In a previous study, ${ }^{16}$ specialists who study dementia provided advice and examined whether the DEOS questions were suitable for measuring the char- acteristics of the "Odayaka scale," thereby confirming the content validity.

\section{Characteristics of subjects and frequency distribu- tion}

\section{5-1. CDR and frequency distribution (Fig. 1)}

The average scores for each of the question items were 3.3 for the CDR 0.5 group, 3.0 for the CDR 1 group, 2.9 for the CDR 2 group, and 2.1 for the CDR 3 group. The average scores for all the questions were lowest for the CDR 3 group (severe level). Except for the CDR 3 group, the average scores for all the questions were similar among the CDR levels. 


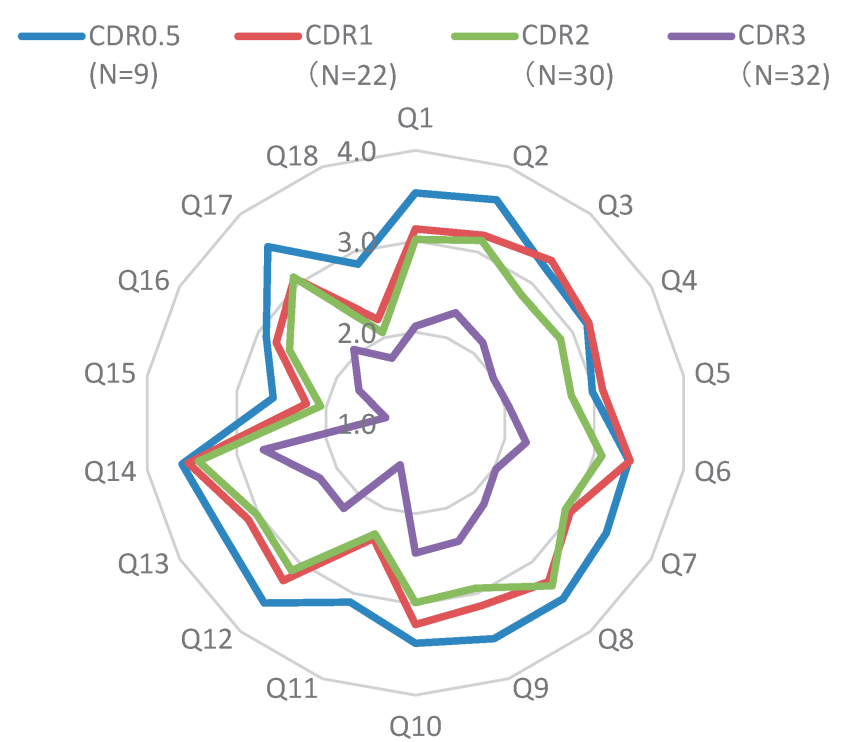

Fig. 1 Averege scores (CDR)

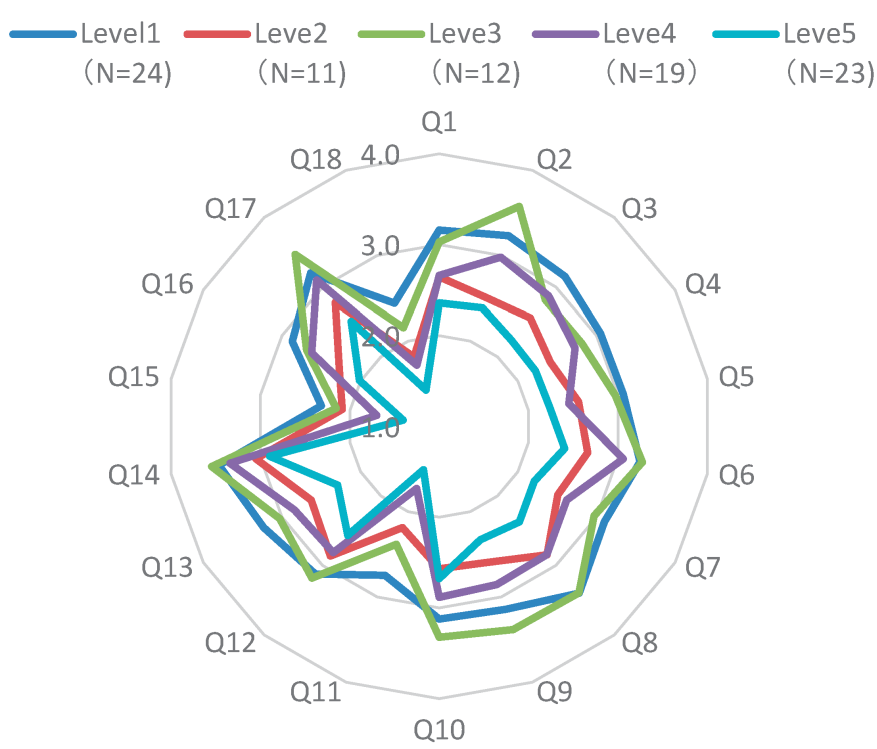

Fig. 2 Averege scores (LTC)

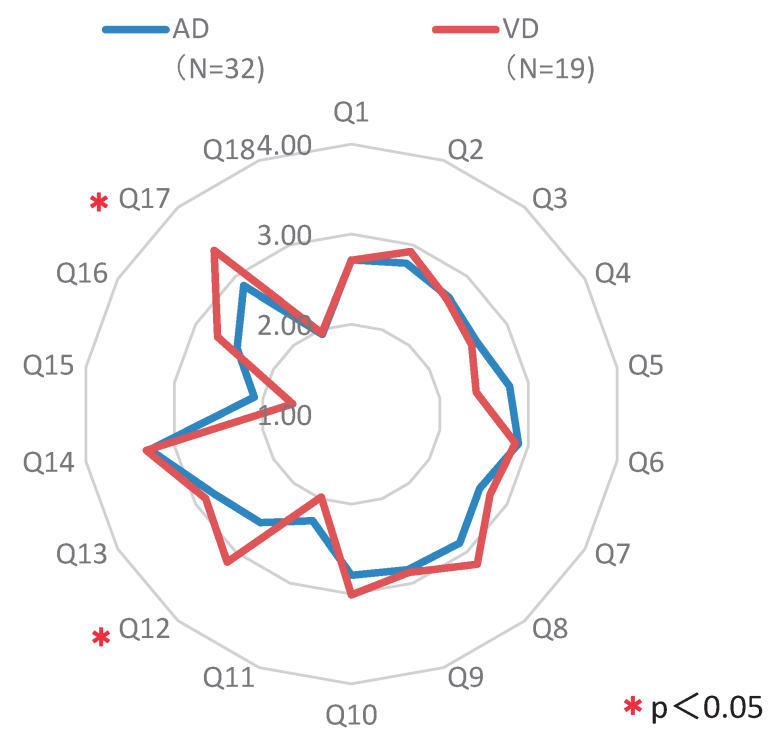

Fig. 3 Averege scores (Diagnosis) 


\section{5-2. LTC and frequency distribution (Fig. 2)}

The average scores for each of the question items were 3.1 for the LTC 1 group, 2.5 for the LTC 2 group, 3.0 for the LTC 3 group, 2.7 for the LTC 4 group, and 2.2 for the LTC 5 group. The average scores for all the questions were lowest for the LTC 5 group. Except for the LTC 5 group, the average scores for all the questions were similar among the other LTC categories. "Being able to express joy with a smile" had the highest average score (3.2) among all the items and also had the highest average score (2.9) among all the items when examined in the LTC 5 group.

\section{5-3. Diagnosis and frequency distribution (Fig. 3)}

When patients with $\mathrm{AD}$ and those with $\mathrm{VaD}$ were compared, the patients with $\mathrm{VaD}$ had high scores for "Being able to insist on one's will and wishes" and "Being able to feel relaxed," while those with AD had a high score for "Being able to do something for others."

\section{Discussion}

\section{Reliability}

\section{1-1. Reliability analysis}

The overall Cronbach $\alpha$ coefficient for the 18-item DEOS was 0.95 , while the $\alpha$ coefficients for all three areas ranged from 0.86 to 0.91 , representing a high level of reliability. The item-total correlation ranged from 0.57 to 0.80 , which was suitable (not too high, not too low).

\section{1-2. Intra-rater reliability}

A test-retest of the evaluations made by the same evaluator confirmed a high reproducibility, and a significantly high correlation was observed between the evaluations made by the nurses and between those made by the family members.

\section{1-3. Inter-rater reliability}

The ICC between the evaluations made by the nurses and those made by the family members ranged from 0.4 to 0.8 , representing a moderate result (not too high, not too low). Furthermore, the average score differences between the nurses' evaluations and between the evaluations made by the nurses and those made by family members were very small. Consequently, the reliability of the 18 -item DEOS was confirmed.

\section{Validity}

Three factors were extracted in the factor analysis. After considering the factor loadings for each item, factor I was named [Personhood], factor II was named [Interactions with surroundings], and factor III was named [Expression of emotions]. These results show a consistency with the definition of odayaka, which means "mental stability, the ability to interact with one's surroundings, and personhood." The items "Being able to interact with surrounding people" and "Being able to do something for others" had relatively high factor loadings. This result is due to the fact that the three regions are not independent of each other and are instead related and have some common features.
After considering the content validity, "Being able to interact with surrounding people" was included in [Interactions with surroundings], while "Being able to do something for others" was included in [Personhood].

Regarding the criterion-related validity of the 18-item DEOS, other existing scales should be used in parallel. In the present survey, however, each evaluator had to perform the same survey twice within two weeks, and further investigations were not requested because of the burden to older caregivers (family members) and busy visiting nurses. However, a subscale of the 25-item DEOS (Tsujimura, Koizumi, 2010) in a previous study ${ }^{16}$ exhibited a significant positive correlation with a QOL scale ${ }^{12}$ and a significant negative correlation with the Behavior and Mood Disturbance scale (BMD). ${ }^{21}$ Therefore, the criterion-related validity of the 25 -item DEOS was confirmed. Since the 18 -items of the 18-item DEOS were selected from the 25 items of the 25-item DEOS, which exhibited significant correlations with other scales, the criterion-related validity of the 25-item DEOS was likely inherited by the 18-item DEOS.

\section{Characteristics of subjects and frequency distribu- tion of DEOS}

The frequency distributions of the DEOS results were examined to determine how they change according to the CDR level and the LTC level (Figs. 1, 2). In either case, the outlines of the figures created by the item frequency distributions of the DEOS were similar, irrespective of the CDR or LTC level. This means that changes in the CDR and LTC levels affect the scores for each item of the DEOS in similar manners. The DEOS had a similar scoring tendency for CDR levels ranging from mild to moderate, and the odayaka of this study was maintained even at a moderate level. The average DEOS scores for each LTC group were similar to those of the CDR groups. Though the score exceeded 3 points for the LTC 1 and the LTC 3 groups, it was 2.5 points or above for the LTC 2 and the LTC 4 groups and was less than 2 points for the LTC 5 group.

For the question items evaluating facial expressions and emotions, such as "Being able to express joy with a smile," the scores were high regardless of the CDR or LTC level. Facial expressions and emotions are considered to be fundamental aspects of human beings as emotional beings, and they are likely to persist throughout one's lifetime. In fact, research into expressions of laughter and smiles in elderly people with severe dementia has been reported. ${ }^{22-23}$

When the patients with AD were compared with those with $\mathrm{VaD}$ in this survey, the AD patients tended to have high scores for items belonging to [Interactions with surroundings], while the patients with $\mathrm{VaD}$ tended to have a high score for "Insisting on one's own will." Further studies examining more data are needed. 


\section{Consideration of construct validity by comparison with previous research}

The same three factors determined in the present study were also extracted in a factor analysis performed in a previous study. ${ }^{17}$ Although the subscales of factor II, [Interactions with surroundings], were similar to those in the previous study, the subscales of factors I and III were somewhat different. The factor [Fulfilling lifestyle] in the previous study was thought to be rather abstract and to encompass a variety of contents. Factor I was named [Personhood], as in the previous study, but the contents of the subscales for Factor III were captured more accurately and named [Expression of emotions]. The factor structures obtained by the factor analysis in the present survey and in the previous study were similar and were consistent with the definition of odayaka. Thus, the construct validity of the scale was confirmed.

\section{Comparison of nurse evaluations performed at facilities and during home visits}

Nurse evaluations performed at facilities and reported in the previous study ${ }^{17}$ were compared with those performed during home visits in the present study. The score differences were less than 1 for all the question items. In addition, the correlation coefficients of the test-retest reliability for the two groups were $0.9 \quad(P<0.01)$ or over. Consequently, a high reliability for the two comparisons was confirmed.

\section{How to use the 18-item DEOS during home care}

The effects of nursing interventions can be evaluated, since high DEOS scores can be expected for patients with a mild to moderate CDR. Also, if subjects have a severe CDR, then the overall DEOS score tends to be relatively low. In this situation, however, full advantage can be taken of the items with high DEOS scores.

In this survey, not only nurses, but also family members participated as evaluators. At home, the main caregiver is often a family member, and nurses need to provide care within a relatively short time. Therefore, the DEOS can be used as an informationsharing tool between the family and nurses. Furthermore, sharing information among nurses can clarify the direction of nursing care and lead to care that takes advantage of the patient's positive aspects. Although caregiver burden is a problem in dementia care, ${ }^{24}$ use of the DEOS could help caregivers to pay attention to positive aspects and to alleviate the burden of nursing care. The DEOS can also be used for persons with mild cognitive impairment (MCI) who live at home.

The DEOS can be used to assess psychosocial aspects of elderly patients with dementia, such as personhood and their relationships with their surroundings. The DEOS can also be used to plan care that takes advantage of the patient's positive qualities also as a scale to evaluate the effects of nursing interventions.

\section{Limits of research and future issues}

In this survey, an evaluation of criterion-related validity was not performed in consideration of the burden to the family members and nurses who participated as evaluators. A detailed diagnosis of dementia had not been performed in many cases, and it was difficult to evaluate the influence of the dementia diagnosis on the DEOS score. In the future, the DEOS is expected to be widely used in actual clinical practice, such as in evaluations of the effects of assessments and care. Furthermore, differences in the use of the DEOS between Japan and other countries need to be examined.

\section{Acknowledgment}

The authors would like to express their gratitude to everyone who cooperated with this research, including the subjects, the family members, the administrators, and the nurses working for home-visit nursing services as well as all the people who provided support and guidance for this study.

\section{References}

1. Ministry of Health, Labour, and Welfare. Number of elderly persons with dementia. (January 31, 2017) http://www.mhlw.go.jp/stf/houdou/2r9852000002iaul-att/ 2r9852000002iavi.pdf.

2. Ministry of Health, Labour, and Welfare. Emergency Project for Improvement of Medical Care and Quality of Life for People with Dementia (January 31, 2017) http://www.mhlw.go.jp/houdou/2008/07/dl/h0710-1a.pdf.

3. Ministry of Health, Labour, and Welfare. Five-Year Plan for Promotion of Measures Against Dementia (Orange Plan). (January 31, 2017)

http://www.mhlw.go.jp/stf/houdou/2r9852000002j8dh-att/ 2r9852000002j8ey.pdf.

4. Ninchisho kaigo kenkyu kenshu Tokyo senta (ed). Ninchisho no hito no tame no keamanejimento senta-hoshiki no tukaikata ikashikata. Tokyo: chuuo hoki shuppan, 2006: 16-45 (in Japanese).

5. Kitwood T. Towards a theory of dementia care: personhood and well-Being. Ageing Soc 1992; 12: 269-287.

6. Imai Y, Kitamura S. Chihousei roujin no QOL to kazoku. Psychiatria et Neurologia Japonica 2000; 11: 498 (in Japanese).

7. Brod MB, Stewart AL, Sands L, et al. Conceptualization and measurement of quality of life instrument: The Dementia quality of life instrument (DQOL). Gerontologist 1999; 39: 25-35.

8. Suzuki M, Uchida A, Kanamori M, et al. Development of the Dementia Quality of Life Instrument-Japanese version. J Jpn Geriatr Soc 2005; 42: 423-431 (Abstract in English).

9. Terada S, Ishizu H, Fujisawa Y, et al. Development and evaluation of a health-related quality of life questionnaire for the elderly with dementia in Japan. Int $\mathbf{J}$ Geriatr Psychiatry 2002; 17: 851-858.

10. Rabins PV, Kasper JD. Measuring quality of life in dementia: conceptual and practical issues. Alzheimer Disease \& Associated Disorders, 1997; 11(S6): 100-104.

11. Rabins PV, Kasper JD, Kleinman L, et al. Concepts and methods in the development of the ADRQL: an instrument 
for assessing health-related quality of life in persons with Alzheimer's disease. J Ment Health Aging 1999; 5: 33-48.

12. Abe T, Yamamoto N, Kamata K, et al. The quality of life of the elderly with dementia Development of the Japanese version AD-HRQL. Psychiatria et Neurologia Japonica, 1998; 9: 1489-1499 (Abstract in English).

13. Yamamoto-Mitani N, Abe T, Okita Y, et al. Development of a Japanese quality of life instrument for older adults experiencing dementia (QLDJ). Int J Aging Hum Dev 2002; 55: 71-95.

14. Honma A. Chihousei roujin no QOL- seisinka no shitenkara. Psychiatria et Neurologia Japonica 2000; 11: 485 (in Japanese).

15. Yamaguchi H (ed). Ninchisho no tadashiirikai to houkatsutekiiryou/kea no pointo. Tokyo: kyodo isho shuppan, 2005: 50-52 (in Japanese).

16. Tsujimura H, Koizumi M. Development of ODAYAKA (Serenity) Scale for Elderly Persons with Dementia. The KITAKANTO Med J 2010; 60: 119-134 (Abstract in English).

17. Tsujimura H, Koizumi M. Application of 18 items DEOS for elderly people with dementia at facilities. Jpn Soc Nurs Res, 2017; 39(4): 89-96 (Abstract in English).

18. Shinmura I (ed). Kojien The 5th ed. Tokyo: Iwanami shoten, 1998 (in Japanese).

19. Marx RG, Menezes A, Horovitz L, et al. A comparison of two time intervals for test-retest reliability of health status instruments. J Clin Epidemiol 2003; 56: 730-735.

20. Hughes CP, Berg L, Danziger WL, et al. A new clinical scale for the staging of dementia. Br J Psychiatry 1982; 140: 566-572.

21. Greene JG, Smith R, Gardiner M, et al. Measuring behavioral disturbance of elderly demented patients in the community and its effects on relatives: a factor analytic study. Age Aging 1982; 11: 121-126.

22. Shirai H, Fujiwara M, Miyaguchi $\mathrm{H}$, et al. Exploratory research into expression of laugh and smile in elders with severe dementia. J Jpn Occup Therapy Assoc 2005; 24: 253-261 (Abstract in English).

23. Miyazaki T, Ga X, Miura K. Research regarding the facial expressions and actions of elderly people with dementia focusing on group home for the elderly with dementia. J Human Life Sci 2012; 11: 9-17 (Abstract in English).

24. Sugiura K, Ito M, Mikami H. Family caregiver burden caused by behavioral and psychological symptoms of dementia: Measurement with a new original scale. Jpn J Geriatr 2007; 44: 717-725 (Abstract in English). 


\section{8 items DEOS}

Subject ID

Evaluator ID

Evaluation date (day/month/year)

Please check the appropriate level of the following items about the recent situation of subject.

1. Being able to interact with the surrounding people

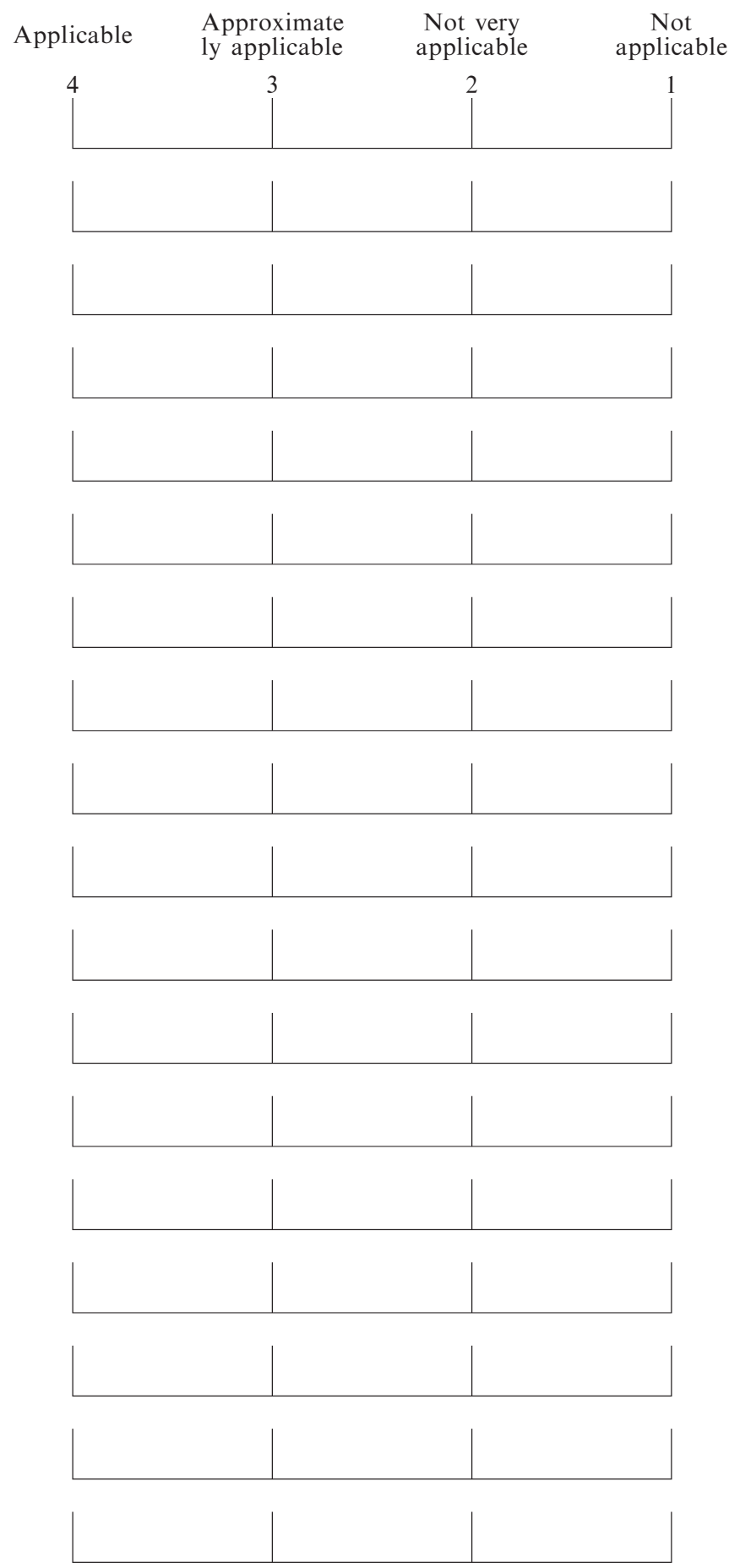

Thank you for your cooperation. 
(Document 2)

\section{8項目版おだやかスケール}

(18項目版 DEOS)

対象者様コード

評価者様コード

評価日（年月日）

対象者様の最近のことを思い浮かべながら下記の項目の該当するところに○印をご記入ください.

1 周囲の人と交流がはかれる

2 人の話を落ち着いて聞ける

3 気のあう人と一緒に過ごせる

4 人のことを気遣える

5 小さな子供やペットを愛しめる

6 他者に優しくできる

7 ユーモアを楽しめる

8 昔話を楽しめる

9 自分のペースで日課を過ごせる

10 感情 (喜びと苦しみなど) を表現できる

11 好きなおしゃれ (化粧, 髪型, 服装, 持ち物) ができる

12 自分の意思や願いを主張できる

\begin{tabular}{llll} 
当 & や & あ & 当 \\
て & ま & て \\
は & 当 & 当 & は \\
ま & $\tau$ & は & ま \\
る & ま & ま & ら \\
4 & ま & な & な \\
4 & 3 & い & い \\
& & 2 & 1 \\
\hline
\end{tabular}

13 人間としての誇りを持っている

14 笑顔で喜びを示せる

15 他人のために何かができる

16 悲観的でなく前向きに過ごせる

17 ゆっくりくつろげる

18 好きなことに打ち込める

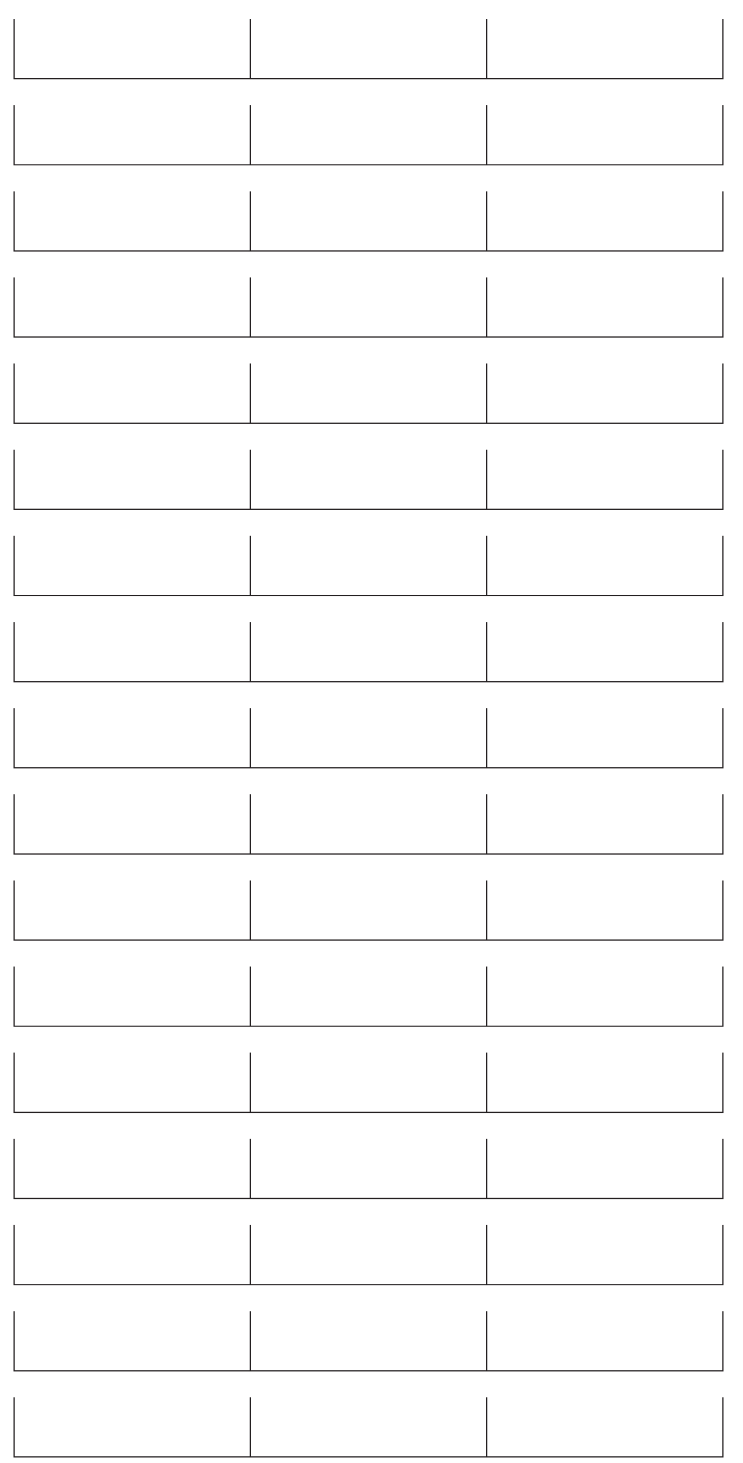

ご協力ありがとうございました 